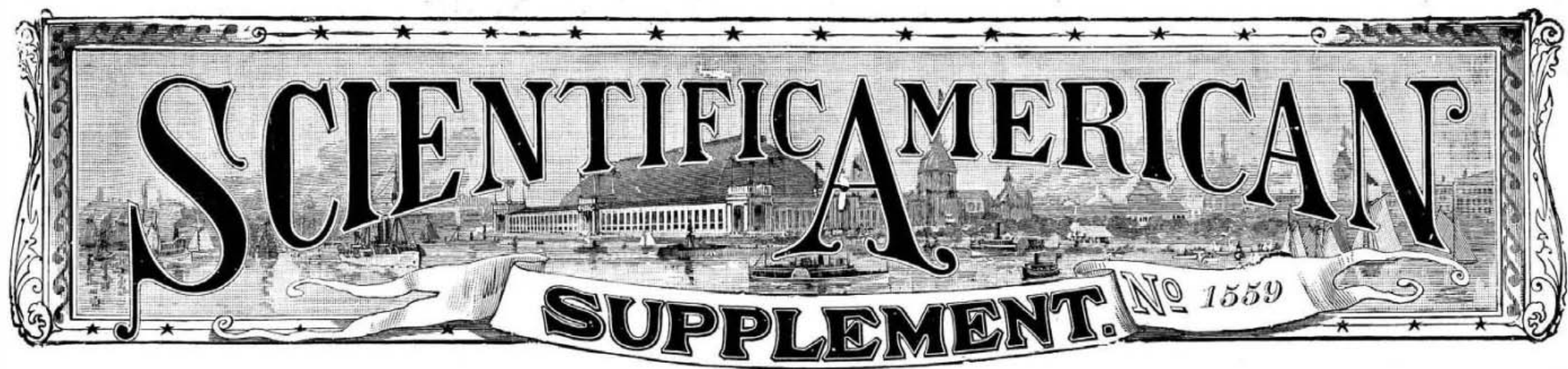

Entered at the Fost Othice of New York, X. Y., as Second Class Matter. Copyright, 1905, by Munn \& Co.

$\left.\begin{array}{l}\hline \hline \text { Scientific American, established 1845. } \\ \text { Scientific American Supplement, Vol. Lx., No. 1559. }\end{array}\right\}$ NEW YORK, NOVEMBER 18, 1905. $\left\{\begin{array}{l}\text { Scientific American Supplement. \$5 a year. } \\ \text { Scientific American and Supplement, \$7 a year. }\end{array}\right.$

THE PRESENT STATUS OF THE PEAT-FUEL neer. While peat and peat-coal plants are by no what it is that makes for success in the present INDUSTRY IN THE UNITED STATES.* means novel, the one under consideration is the first

By A. Frederick Collins. is due to a number of vital factors that seem to have peat is understood. What is termed peat is simply a Wнат with the recent address of President Roose- been entirely overlooked by those who have attempted velt to the Pennsylvania miners, the concealment bv to enter this field in the past. the Coal Trust of thou. sands of tons of anthracite, and the statement of John Mitchell to the effect that unless the demands of his union are complied with a strike will take place in the spring it is small wonder that the con sumers of this commodity at large are sore afraid they will run amuck of another fuel famine.

The price of anthracite The price of anthracite commodity must know, is com steadily ring, is the chances of the usual pring reduction of 50 cents a ton, in consecuving advanced the prors per ton the price per ton ten cents on five different occasions, pracduction of 65 cents by the retailers has been wiped out by four advances, so that as the market now stands it is delivere by the operators free on board at $\$ 5$ per
ton, while the quotaton, while the quotation of $\$ 6.25$.

is $\$ 6.25$.

Under these circum stances, then, it is well to direct public attention to a new fuel plant that has taken root and is now being carefully watched by experts as well as the coal barons at New Rochelle, N. Y. This is the equipment of the Peat-Koal Company, installed a year or so ago under the direction of Mr. H. H. Wotherspoon, Jr., the ell-known fuel engi-

* Specially prepared for the
AcIENTIFIC AMERICAN SUP-

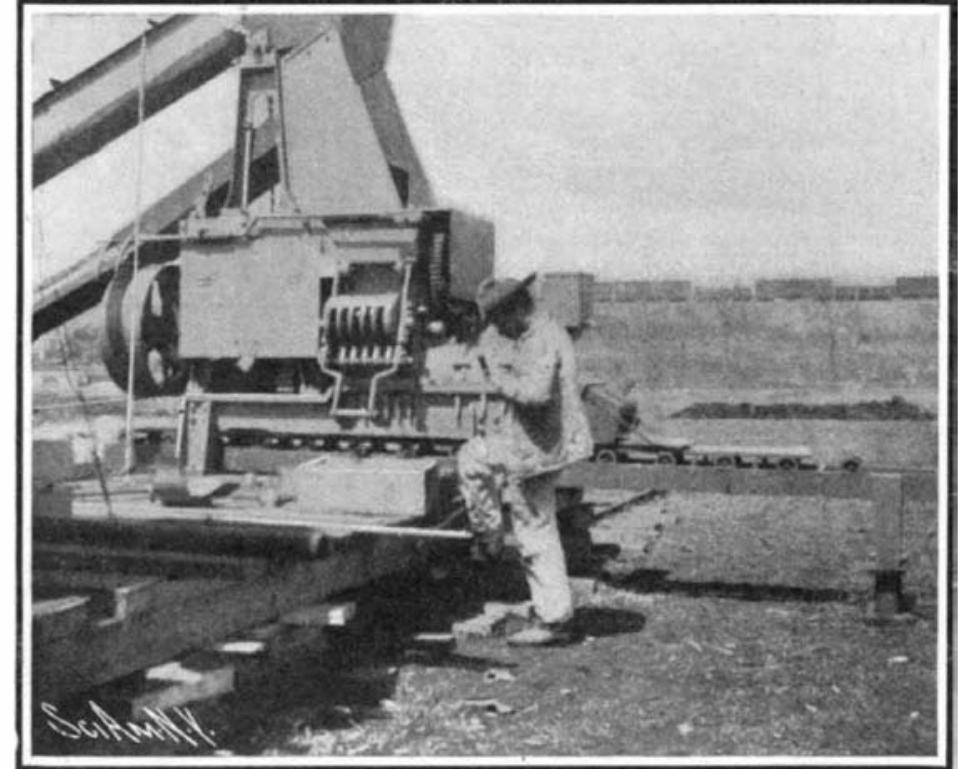

SIDE VIEW OF THE BRIQUETTING MACHINE.

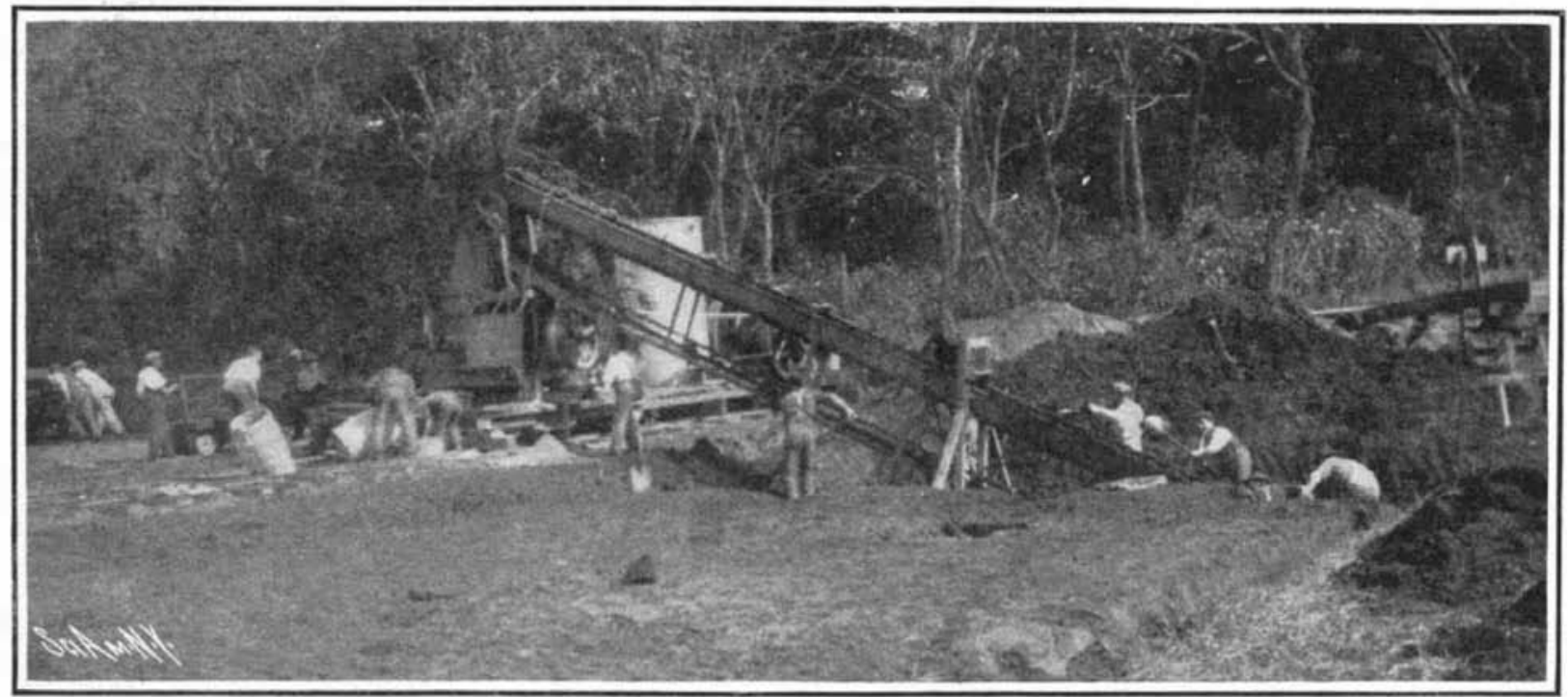

CONVEYING PEAT FROM THE BOG TO THE MACHINE WHERE IT TS BRIQUETTED.

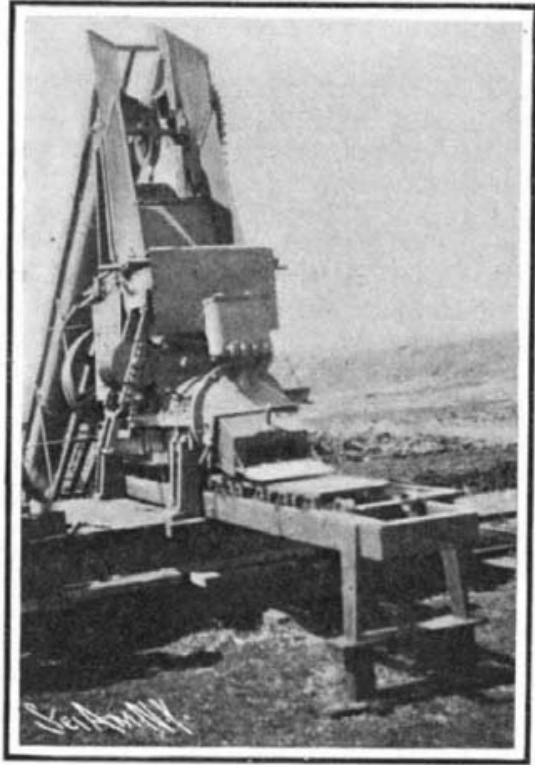

FRONT VIEW OF THE BRIQUETTING THE BLOCKS ARE FORMED.

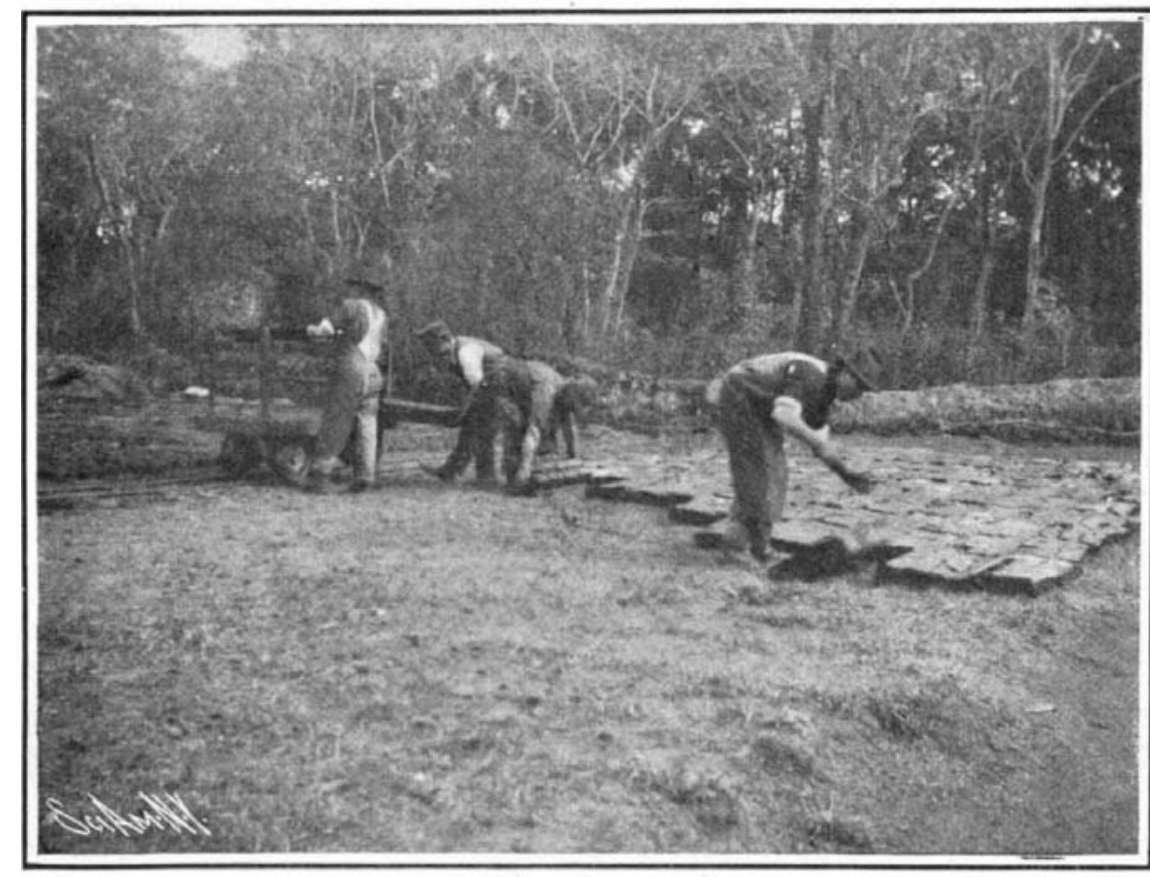

DUMPING THE BRIQUETTES ON THE GROUND TO DRY.

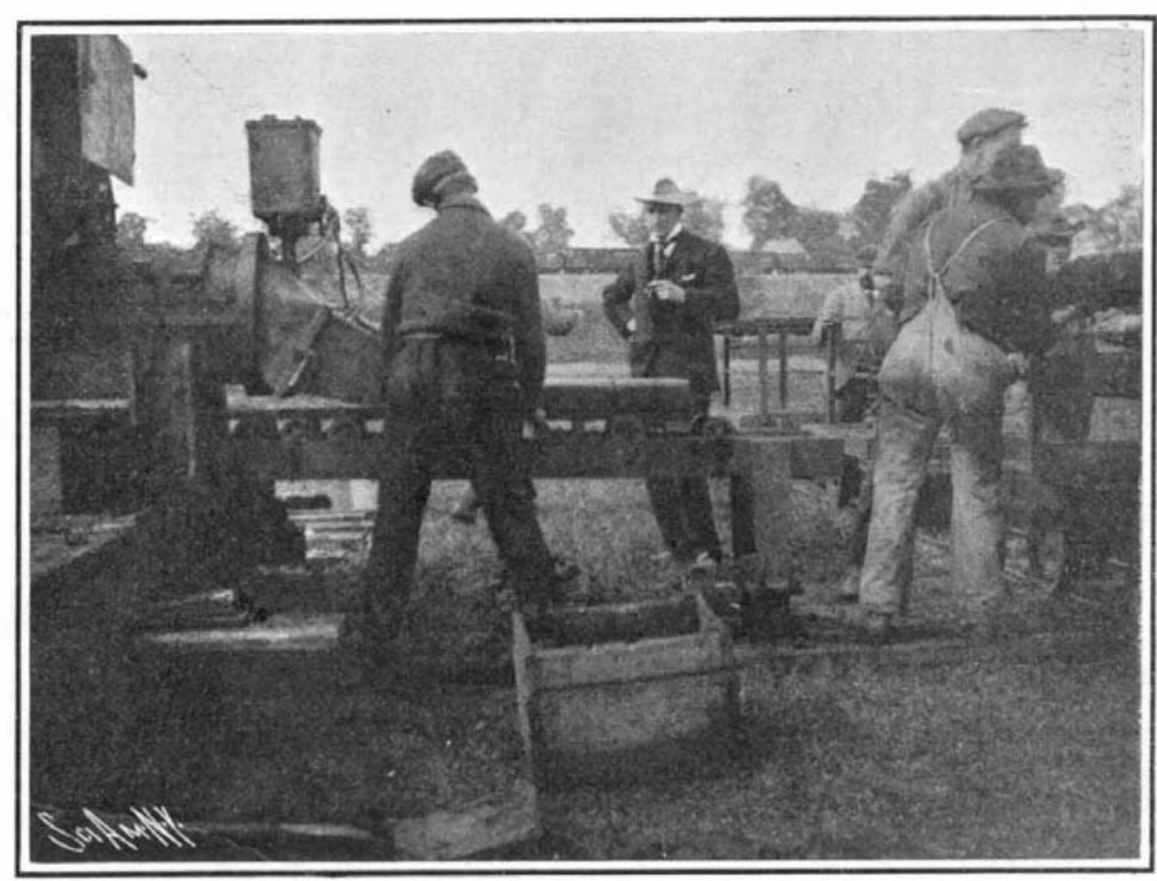

THE BRIQUETTES AS THEY ISSUE FROM THE MACHINH. grow profusely on top of the bog, but as these succumb to the elements they are submerged; and rapidly, peat is produced, varying from one to five inches a year, until the depth of the bed may ange from 10 to 40 feet. While peat beds are and southern temperate zones, they occur most frequently in the former, especially where sphagnum mosses grow. In tho tropics such bogs are not found, for the reason that the vegetable material decomposes too quichly to permit it to properly carbonize. Throughout the temperate regions of the north, where the conditions are conducive to the formation of peat, as in nental Europe, there are millions of a cres, while in Canada and $\mathrm{t}$ h e United States there are even larger In Europe, especially in those countries where there is little or no coal to be likewise and wood is oxpensive have been operated systematic a 11 y for many years as an allaround fuel. Many attempts have bee $\mathrm{n}$ made in America to man ufacture compressed peat brimethod has in this instance proven unsuccessful, since coal under normal condions is comparatively 'iHe PREsent status OF THE PEAT-FUEL INDUSTRY IN THE UNITED STATES. 
cheap, and any process of peat-fuel making that utilizes more than ordinary pressure or employs heat to pact, must of necessity fail, for in these lie the prohibitive sources of expense.

In Holland, Germany, and other foreign countries where the most successful peat plants in the worl are in operation, these untoward features have lon ago been cast out, and the simplest method has been
found not only the cheapest, but the best as well. This plan has just been introduced into this countr by Mr. H. H. Wotherspoon, Jr., the peat-fuel engin after an exhaustive study of the situation abroad.

First as to the nature of peat and its environments. In a good bog the carbonized material is very black and dense immediately under the surface. As there are considerable quantities of tannic and other acids, various salts and iron in the deposits, all of which have a tendency to preserve the vegetable matter, the beds are practically valueless for farming; but oppositely disposed, the excellent condition of the fibers of the plants has led to experiments looking towar such investigations have not worked out commercially, and hence the only value of such land is for the making of fuel.

When vegetation such as grasses, shrubs, and mosses is exposed to the effects of the elements, they give of their gases very quickly, nitrogen in the largest amount, some hydrogen, and a little oxygen; whereas if the plants above named are inundated with stag nant water, the only gas that is liberated is marsh gas, a stable colorless compound formed by one atom of carbon and four atoms of hydrogen. The proportion of carbon in the peat thus lost is exceedingly small, and thus the greater amount of this valuable
element, which is the portion required for burning, is element, which is the por
stored up for future use.

Peat beds then may be looked for wherever there are swamps or other poorly drained land, and the decomposed matter forms in a literal sense a vein of coal in the early stages of making. Although decomposed, the plants retain to a considerable extent their fibrous qualities, and these absorb large amounts of
water. By the chemical action that takes place, a peculiar adhesive property is evolved, and it is this peculiar adhesive property is evolved, and it is this principle that plays so important a part in the mak-
ing of peat fuel. This substance is as sticky as glue, and is known technically as pentazone.

To pentazone is due in no small measure much of the ill success that has attended the different processes utilizing furnaces as a means for expelling the
moisture from the freshly briquetted product, for the moment heat is applied in excess of 100 deg. Fahren heit, it loses its value as a binder, and hence high temperatures are not only expensive but destructive.
Permitted to dry in the open air and under the gentle Permitted to dry in the open air and under the gentle
influence of the sun, the pentazone quickly hardens, when the particles of peat are rigidly bound together The first plant to be operated in this country wherein the above conditions have been rigorously observed
is at New Rochelle, $\mathrm{N}$. $\mathrm{Y}$, where the Peat-Koal Comis at New Rochelle, N. Y., where the Peat-Koal Com-
pany is now commercially converting the black mud into good fuel by a process that is at once efficient, simple, and cheap. Here the peat as it is dug from the bog is carried by an endless belt conveyor to a reduction machine, which will presently be described in detail, and wherein three different operations take place, that is, it breaks up the decomposed mass, then which frees the pentazone, and lastly works o.ver the material, when 15 per cent of the water it contains is removed, after which the green fuel is forced from the machine.

As the peat continually emerges it is cut off into desirable lengths, and then spread out in the open on the ground. Whatever water now remains is evapprocess requiring from fifteen to twenty days; the dry ing is naturally attended by shrinkage in weight and volume, but the final result is a black, brittle, and compact mass having nearly the specific gravity of bituminous coal, but which is as

The new plant is located near the tracks of the Harlem division of the New York, New Haven \& Harlem division of the New York, New Haven \&
Hartford Railroad, where the company owns and controls 25 acres of bog land that has heretofore been deemed valueless; yet according to Mr. Wotherspoon its quality is superior to the best that Germany has to offer. Tests have shown that the bog has an average
depth of about 25 feet, while at the center it has a depth of about 25 feet, while at the cen
maximum depth of approximately 40 feet.

To prepare the bog for excavating, the growth of vegetation was plowed up, and then it was drained by a series of ditches leading to a common center, where
the water is forced out by means of a small centrifugal pump driven by a kerosene engine, whence it is conveyed to a nearby stream.

That the element of uncertainty might not enter into the introduction of peat-fuel making in this coun-
try, the most successful device, and one that has been try, the most successful device, and one that has been
in operation for the past twenty-five years in Gerin operation for the past twenty-five years in Gerple but powerful machine of Schlickeysen. The machine is fed by men who shovel the peat into a trough conveyor, which connects the hopper with the pit; the machine proper comprises three distinct elements, namely, a disintegrator, a reduction mill, and a rotating screw, the latter delivering the soft cohering mass through an orifice or die havin
allel, and longitudinal divisions.

As the freshly-formed square layers of pulp issue forth they are run out on individual boards, each capable of holding 12 briquettes, where they are cut
into blocks about 12 inches in length. The boards with the blocks upon them are carried to small in dustrial cars, the last named being pushed by han around the yard to convenient points for drying when they are dumped.

The mill weighs three tons, and contains all the latest improvements, such as ejectors for throwing out stones and other foreign substances before they can
reach the disintegrating beaters or the reduction reach the disintegrating beaters or the reduction knives. A 15-horse-power kenosene engine drives the machine, and this is much more economical than a steam engine, for no licensed engineer is needed, and the kerosene consumed during a run of ten hours amounts to only $\$ 1.75$. Both engine and mill are mounted on the same platform, thus forming a compact unit; the platform rests on a track, and by this arrangement they may

The workmen dig out from one side to the other of the bog, a pit that measures 20 feet wide, but when the peat is removed to a depth of 5 feet, another pit until the entire bog has been excavated. When this is done, the operation is begun all over again, and this may be repeate

The mill is capable of turning out 6,500 blocks per hour; of the weight these represent, about 85 per cent is water. In a couple of hours after these are spread out to dry, 10 per cent of the moisture will be found to have evaporated, and the blocks are now found to have evaporated, and the blocks are now
strong enough to be handled. Usually a few days are permitted to elapse before they are arranged in small permitted to elapse before they are arranged in small
loose piles, so that the air can freely circulate through loose piles, so that the air can freely circulate through
them," and in another two hours an additional 10 per cent of the water contained is lost. As the drying goes on, more time is required for its final eliminagoes on, more time is required for its final elimina-
tion. If the days are dry and the sun shines brightly, fifteen days may suffice to render them fit for fuel, therwise eighteen or twenty days will be required.

It is obviously clear that where compression is not attempted, and where nature is made to do the work nstead, there is a large saving effected as against obviously true that the process under consideration requires a considerable length of time, but this is of no particular moment, for the bog itself offers ideal conditions for spreading out and arying hundreds of tons of the briquettes. The advantages of. this mode of procedure may be restated by saying that where
compression is resorted to, the peat is pressed into layers, and a brick so produced has not nearly the enduring qualities of the brick obtained by the con-
traction of its fibers through the agency of time and

As the blocks come from the mill they weigh about
As pounds and have a volume of 120 cubic inches, but after the water has becn evaporated they are reduced in size until they weigh 1.3 pounds and have a volume of 24 cubic inches. In a brick that is ready to burn there still remains 12 per cent of water, but this is chemically combined with the other ingredients. A this percentage may vary, it has been suggested that
it should be sold by cubic measure instead of by weight, and in small lots this is done.

It will readily be seen that the expense of operation is reduced to a minimum, and the appended figures present time 25 men have been at work in this primltive, yet paradoxical, up-to-date coal mine. The out-
put is between 30 and 35 tons per day, and the cost of production ranges from $\$ 1.50$ to $\$ 1.75$ per ton.

This bog product has been called an emergency peat coal weighing one pound each will cook a breakfast for four people at a total cost of 12 mills, and that there are peat bogs everywhere, it indicates that this is the natural fuel, and as such it will supplant the former knocks the pedestal from under the coa barons, and they reduce the price to a marked degree It may be asked what becomes of the plant when the bog is exhausted. One of the advantages of a the bog is exhausted. One of the advantages of a
peat plant of this character is that it requires no perpeat plant of this character is that it requires no per
manent fixtures. The machinery is easily moved, and manent fixtures. The machinery is easily moved, and the few buildings that are required are of the "knockdown" type, that is they can be put up or taken apart
without the use of a nail. While the work is in without the use of a nail. While the work is in
progress the bog is of course drained, but when all progress the bog is of course drained, but when all
the peat is removed, the water is permitted to flow in, filling the hole, a small artificial lake is made, and cutting furnishes another enterprise.

The mills may be had in all sizes, capable of turn ing out, from No. 3, 35 tons per day, and every farme just as he has his own power and his own garden. This and the cheapness of the product are reason why it is likely that the peat in
formidable rival to the coal trust.

Coal mines are localized in a few districts through out the country, and the properties are not only of exceeding value, but the monopolists have them all
securely within the hollow of their hands, as well as the carriers which transport this commodity; but since peat bogs are everywhere, machines are readily available, and the operation of such plants requires no skilled labor; certainly communities, however large or small, will not be coerced always into paying high
prices for coal, with occasional extraordinary prices prices for coal, with occasional extraordinary prices ing for their very lives.

There are twenty-five million tons of bog fuel within radius of ten miles from New York city, and this gigantic deposit, as we have seen, may be transformed to fuel for $\$ 1.75$ per ton, and probably much cheaper. In every section of the country there are dormant they are worth nothing as they now stand. The grass meadows and swamps of this country are mines a rich as those in the gold fields of the Klondike, and are capable of being converted into light, heat, and power, with by-products of great importance.

\section{OTTER FURS.*}

By Chardes H. STEverson.

THE fur of the otter is short, abundant, and of fine quality. It is slightly waved and silky and is similar in appearance to that of the beaver, but is somewhat
shorter and more delicate and glossy. The fur on the stout tail is of the same character as that on the body, but not so long. That on the body is of a whitish-gray for two-thirds of its length from the base, rich brown at the tips, and is interspersed with stiff, thick over hairs similarly colored. The general color of the overhairs is brown above and a little whiter beneath, with chin and throat whitish. The shade of brown varies according to the locality in which the animal lives; in eastern Maine this is almost black; in Canada, Nova
Scotia, and Labrador it is dark brown; in Alaska and Eritish Columbia the animal is light brown. The fur on the throat, under parts, and inner surface of the legs is usually of various shades of brown. White or zly, mottled, and slate-colored are met with at times.

$$
\text { TRADE IN OTT-R SKINS. }
$$

The early trade in otter skins in America, although never so extensive, was almost contemporaneous in its development with the trade in beavcr furs. In the
operations of the early fur-traders in the present limits operations of the early fur-traders in the present limits
of the United States many otters were obtained. It appears, however, that the capture of these was merely incidental to the taking of beaver. Indeed, during the
first hundred years of the exploitation of America the first hundred years of the exploitation of America the
beaver was almost the only fur-bearing animal whose capture was a special object of industry. Later, how ever, with the increase in value of the pelts, the otter became an object of special pursuit, and by 1777 the
industry reached an extent from which it has varied industry reached an extent

ittle up to the present time.

It is quite remarkable that the number of otter skins which are handled annually at the London sales should have fluctuated so little during the last 140 years. From 1763 to 1900 the annual quantity exceeded 30,000 only twice, and it fell short of 8,000 the same number of times, and the average by deca

With the exception of nutria, a smaller proportion of the total product of otter skins are now handled at the London sales than in case of any other aquatic fur, sold there. The others are sold at Leipsic or directly to the furriers of the United States and Canada. The best local markets for otters are in Russia and Greece, where Out of a total of 7,865 otter skins sold in London in
March, 1901, 3,293 were No. 1; 2,498 were No. 2; 1,318 were No. 3, and 756 were cubs. The No. 1 averaged in value $28 \mathrm{~s}$. $6 \mathrm{~d}$; the No. $2,20 \mathrm{~s}$. $6 \mathrm{~d}$.; the No. $3,12 \mathrm{~s}$. 1 .,
and the cubs $5 \mathrm{~s}$. $6 \mathrm{~d}$. per skin. These prices were someand the cubs 5s. 6d. per skin. These prices were some-
what less than the average in 1900 . The highest price secured at the 1901 sale was $115 \mathrm{~s}$. each for a lot of 42 skins, while the lowest price was $3 \mathrm{~s}$. each for a lot 42 skins, while the lowest price was 3 s. each for a lot
of cubs, and also for a number of part pale No. 3. Exof cubs, and also for a number of part pale No. 3. Ex-
clusive of the cubs, those of a brown color numbered clusive of the cubs, those of a brown color numbered
269 , while 301 were partly brown, 693 pale, 1,691 partly pale, and the remaining 4,155 of the distinctive dark otter color.

DRESSING OTTER SKINS,

When received at the fur-dresser's, otter skins are almost invariably cased, and are first cut open longi-
tudinally down the chest and abdomen. The pelt is tudinally down the chest and abdomen. The pelt is
soaked in salt water over night for the purpose of soaked in salt water over night for the purpose of
softening it and preparing it for "breaking." The following morning each skin is placed on a beam, and a workman proceeds to break up the grain of the membrane. The pelt is now washed in warm soap water and the water removed, as in the case of beaver skins. If the overhairs are to be plucked, that is done next. The choicest skins are left "in the hair," the number dressed.

The pelt, which has become less bulky and quite soft rom frequent handling, is now placed on a beam and Mlowed It is next dampened with cold salt water and it is stretched lengthways and crossways and partly dried, when it is ready for the leathering process. It is well rubbed with butter, or some other animal where it is worked for hours. On removal the skins are revolved for three or four hours with a quantity of hard-wood sawdust in a cleaning drum, under which there is steam heat or a charcoal fire. Next they are
placed in tubs with a quantity of sawdust, where they placed in tubs with a quantity of sawdust, where they
are tramped for about three hours by barefooted workmen and on removal are thoroughly stretched. The men and on removal are thoroughly stretched. The then shaved down to a uniform thickness as in case then shaved down to a uniform thickness as in case
of beaver skins. A skillful workman can shave thirty or forty otter pelts in a day. The skins are then 